\title{
Expression and function of IncRNA MALAT1 in gestational diabetes mellitus
}

\author{
*Yan Zhang ${ }^{B}$, ${ }^{*}$ Liping Qu $^{\mathrm{F}}$, Huijie Nii, Yuping Wang ${ }^{\mathrm{C}}$, Lei Li ${ }^{\mathrm{D}}$, Xiaowei Yang ${ }^{\mathrm{E}}$, Xiao Wang ${ }^{\mathrm{A}}$, Yuanyuan Hou ${ }^{\mathrm{A}}$ \\ Department of Obstetrics, Yantai Yuhuangding Hospital, China \\ A - research concept and design; $B$ - collection and/or assembly of data; $C$ - data analysis and interpretation; \\ $D$ - writing the article; $E$ - critical revision of the article; $F$ - final approval of the article
}

\section{Address for correspondence}

Yuanyuan Hou

E-mail: vslkpqbjfefkl@sina.com

\author{
Funding sources \\ None declared \\ Conflict of interest \\ None declared \\ *Yan Zhang and Liping Qu contributed equally \\ to this work.
}

Received on 0ctober 22, 2018

Reviewed on January 24, 2019

Accepted on April 30, 2020

Published online on August 12, 2020

\begin{abstract}
Background. Gestational diabetes mellitus (GDM) severely threatens maternal and fetal health. Long noncoding RNA (IncRNA) participates in the regulation of various cellular processes.

Objectives. Previous studies have identified the role of IncRNA MALAT1 in diabetic retinopathy-related inflammation. However, the role of IncRNA MALAT1 in GDM has not been reported yet.

Material and methods. Real-time polymerase chain reaction (RT-PCR) was used to measure the IncRNA MALAT1 expression level in placental tissues from GDM patients and from a normal pregnant group. Placental trophoblastic-derived cell line HTR8 cells were divided into a control group, an siRNA negative control group and a MALAT1 siRNA group. The cells underwent RT-PCR analysis of IncRNA MALAT1 expression, an MTT assay of cell proliferation, and a transwell assay of cell invasion and migration. In addition, enzyme-linked immunosorbent assay (ELISA) was used to analyze the level of tumor necrosis factor a (TNF-a) and interleukin 6 (IL-6). Western blotting was used to measure the changes of the tumor growth factor $\beta$ (TGF- $\beta$ )/nuclear factor-kappa B (NF-kB) signaling pathway.
\end{abstract}

Results. Gestational diabetes mellitus placental tissues showed higher IncRNA MALAT1 expression compared to a normal control group $(p<0.05)$. After siRNA intervention, IncRNA MALAT1 showed decreased expression in the trophoblastic layer; inhibited trophoblastic cell proliferation, migration, or invasion; decreased the secretion of inflammatory factors TNF- $\alpha$ and IL-6; and suppressed the expression of TGF- $\beta$ and NF-KB compared to that of the control and siRNA-NC groups $(p<0.05)$.

Conclusions. Gestational diabetes mellitus appears to upregulate IncRNA MALAT1. Downregulation of IncRNA MALAT1 inhibits inflammation and suppresses the proliferation, invasion and migration of GDM placental trophoblastic cells, possibly by modulating the TGF- $\beta / N F-K B$ signaling pathway.

Key words: gestational diabetes mellitus, IncRNA MALAT1, TGF-B/NF-kB signal pathway, cell proliferation, cell migration

Cite as

Zhang Y, Qu L, Ni H, et al. Expression and function of IncRNA MALAT1 in gestational diabetes mellitus. Adv Clin Exp Med. 2020;29(8):903-910. doi:10.17219/acem/121524

DOI

10.17219/acem/121524

\section{Copyright}

Copyright by Author(s)

This is an article distributed under the terms of the

Creative Commons Attribution 3.0 Unported (CC BY 3.0)

(https://creativecommons.org/licenses/by/3.0/) 


\section{Introduction}

Gestational diabetes mellitus (GDM) is frequently caused by abnormal glucose resistance or impairment during the gestational period, and mainly presents as elevated fasting blood glucose and insulin resistance, accompanied with inflammation, increased secretion of inflammatory factors and abnormal body immunity. ${ }^{1,2}$ Gestational diabetes mellitus is a unique subtype of diabetes which occurs in pregnant women worldwide. ${ }^{3}$ With differential incidence, European countries usually have a GDM prevalence of about $4 \%$ and China now has a GDM incidence of about 3\%. With lifestyle change and more focus on gestational nutrition, GDM incidence has been continuously increasing over the years. ${ }^{4,5}$ Gestational diabetes mellitus patients have elevated glucose levels and glucose catabolic disorder, caused by insulin resistance and leading to cellular glucose metabolic disorder. On the other hand, GDM can cause increased production of reactive oxygen species (ROS) and oxygen free radicals, further leading to oxidative stress and maternal/fetal injury. Elevated blood glucose during pregnancy can cause vascular disease, impair vascular endothelial proliferation and inhibit placental angiogenesis, leading to abnormal placenta blood circulation and placental abnormality caused by ischemia/hypoxia as the result of pathological changes in the placental cells. ${ }^{6-8}$ In short, GDM can cause placental abruption, gestational hypertension, premature delivery, or congenital abnormality, leading to severe and long-lasting threats to maternal/fetal health. ${ }^{9,10}$ Recent studies have found that long noncoding RNA (lncRNA) participates in the regulation of various cellular processes. For example, lncRNA MALAT1 has been shown to play roles in diabetic retinopathy and related inflammation. ${ }^{11} \mathrm{How}-$ ever, whether lncRNA MALAT1 plays a role in the development and pathogenesis of GDM remains poorly understood. In the present study, we aimed to uncover the role of lncRNA MALAT1 in GDM and to provide a theory for a novel therapeutic target in the treatment of GDM.

\section{Material and methods}

\section{Research subject recruitment}

A total of 78 women with a confirmed diagnosis of GDM in Yantai Yuhuangding Hospital (China) between June 2016 and December 2017 were selected for the study. All GDM patients were diagnosed with an oral glucose tolerance test (OGTT) from gestation weeks 24 to 28. All patients matched the diagnosis criteria of GDM as stipulated by the World Health Organization (WHO) in $2013 .{ }^{9}$
The exclusive criteria included ${ }^{10}$ multiple pregnancy; incompatibility of maternal and fetal blood types; history of surgical operations (including laparoscopic surgery, open surgery and keyhole surgery); complications such as inflammation, malignant tumor, severe diabetes, organ failure, systemic immune disorder, or malignant tumor complications. Furthermore, women who were receiving chemotherapy or radiotherapy or had other gestational complications - such as hypertension, exposure to toxic substances during pregnancy, or an abnormal placental or umbilical cord - were also excluded from the study. A cohort of 38 normal pregnant women was recruited as the normal control group. Informed consent was obtained from all participants prior to the study. This study has been approved by the ethical committee of Yantai Yuhuangding Hospital (China). All placental samples were collected from the maternal side of the placenta after delivery. Small tissue cubes were collected and kept in cryopreserved tubes in liquid nitrogen.

\section{Major equipment and reagents}

Placental trophoblastic derived cell line HTR8 was purchased from ATCC (CRL-3271; Manassas, USA). An RNA extraction kit and reverse transcription kit were purchased from R\&D Systems, lnc. (Minneapolis, USA). Other common reagents were purchased from Sangon Biotech (Shanghai, China). Real-time polymerase chain reaction (RT-PCR) reagent was purchased from Thermo Fisher (Waltham, USA). Dulbecco's modified Eagle's medium (DMEM), fetal bovine serum (FBS) and penicillin-streptomycin were purchased from Hyclone (Chicago, USA). Dimethyl sulfoxide (DMSO) and MTT powder were purchased from Gibco (Waltham, USA). Trypsin-EDTA digestion buffer was purchased from Hyclone. Western blot reagents were purchased from Beyotime (Haimen, China). Enhanced chemiluminescence (ECL) reagent was purchased from Amersham Biosciences (Little Chalfont, UK). Rabbit antihuman nuclear factor-kappa B (NF-kB) monoclonal antibody, rabbit anti-human tumor growth factor $\beta$ (TGF- $\beta$ ) monoclonal antibody, and mouse anti-rabbit horseradish peroxidase (HRP)-conjugated IgG secondary antibody were purchased from Cell Signaling Technology (Leiden, the Netherlands). Enzyme-linked immunosorbent assay (ELISA) kits for measuring the level of tumor necrosis factor $\alpha$ (TNF- $\alpha$ ) and interleukin 6 (IL-6) were purchased from Cell Signaling Technology. siRNA was synthesized by Gimma Gene (Shanghai, China). A transwell chamber was purchased from Corning (New York, USA). A RT-PCR cycler was purchased from Applied Biosystems (Waltham, USA). A Gene Amp PCR System 2400 DNA amplification cycler was purchased from Perkin Elmer (Waltham, USA). A $371 \mathrm{CO}_{2}$ cell incubator was purchased from Thermo Fisher. 


\section{HTR8 cell culture and grouping}

An HTR8 cell line kept in liquid nitrogen was resuscitated and cultured for passage. Cells in log-growth phase at generations 3-8 were used for assays. The HTR8 cells were kept in $90 \%$ high-glucose $(25 \mathrm{mmol} / \mathrm{L})$ complete medium plus $10 \% \mathrm{FBS}$ for attached growth. The cells were then randomly assigned into 3 groups: a control group, which was cultured under normal conditions; an siRNA-NC group that was transfected with lncRNA MALAT1 negative control (NC) plasmid; and an siRNA group which received lncRNA MALAT1 siRNA transfection.

\section{Liposome transfection of IncRNA MALAT1 siRNA into HTR8 cells}

HTR8 cells were transfected with lncRNA MALAT1 siRNA or siRNA-NC. The sequence for IncRNA MALAT1 siRNA was 5'-GAGGA GUGCA GUUCU UCA-3', and the sequence for siRNA-NC was 5'-GACAG UGUGA UUCUA-3'. The cells were seeded into 6-well plates and cultured until 70-80\% confluence was reached. Plasmid for lncRNA MALAT1 siRNA or NC control was added into $200 \mu \mathrm{L}$ of serum-free DMEM for $15 \mathrm{~min}$ at room temperature for incubation, which was added into a dilution buffer along with Lipo2000 reagent and incubated for $30 \mathrm{~min}$ at room temperature. Serum was removed from the culture medium, and the cells were rinsed gently in PBS. Another $1.6 \mathrm{~mL}$ of serum-free DMEM was added into the system, and the cells were incubated in a chamber at $37^{\circ} \mathrm{C}$ with $5 \%$ $\mathrm{CO}_{2}$ for $6 \mathrm{~h}$. Serum-containing DMEM medium was then used for 48-hour continuous incubation for the assays.

\section{RT-PCR for IncRNA MALAT1 in GDM placental tissues and HTR8 cells}

Trizol reagent was used to extract total RNA from the placental tissues of GDM patients or normal placental tissues, or from HTR8 cells in all groups. The RNA was then reverse transcribed into cDNA according to the instructions of the test kit. The primers were designed using PrimerPremier v. 6.0 (Premier Biosoft, San Francisco, USA) based on the target gene sequence, and they were synthesized by Invitrogen (Carlsbad, USA), as shown in Table 1. Real-time PCR was performed on the target genes under the following conditions: $55^{\circ} \mathrm{C}$ for $1 \mathrm{~min}$, followed by 35 cycles consisting of $92^{\circ} \mathrm{C}$ for $30 \mathrm{~s}, 58-60^{\circ} \mathrm{C}$ for $45 \mathrm{~s}$, and $72^{\circ} \mathrm{C}$ for $45 \mathrm{~s}$. Data was collected to calculate the threshold cycle $(\mathrm{Ct})$ values of all samples and standard samples using fluorescent quantification. Based on the CT values of the standard samples, the standard curve was plotted and semi-quantitative analysis was performed using the $2^{-\Delta \mathrm{Ct}}$ method.

\section{MTT assay for cell proliferation of all groups}

HTR8 cells in the log-growth phase were inoculated into 96-well plates using DMEM medium with 10\% FBS at a density of $5 \times 10^{3} /$ well. After $24 \mathrm{~h}$ of incubation, the supernatant was discarded and all wells were filled with $20 \mu \mathrm{L}$ of sterile MTT. Three replicated wells were performed at each time point. After $4 \mathrm{~h}$ of continuous incubation, the supernatant was discarded and $150 \mu \mathrm{L}$ of DMSO was added into each well for $10 \mathrm{~min}$ of vortex mixing. After complete resolution of violet crystals, absorbance (A) values were measured at a wavelength of $570 \mathrm{~nm}$ under a microplate reader in order to calculate the proliferation rate of all groups.

\section{Transwell chamber assay for measuring invasion from all groups of cells}

A transwell invasion assay was performed according to the instruction manual. Serum-free medium was used. After $24 \mathrm{~h}$, the transwell chamber was pre-coated with 1:5 $50 \mathrm{mg} / \mathrm{L}$ Matrigel dilution buffer on the chamber bottom and the upper phase of the membrane, and the chamber was air-dried at $4^{\circ} \mathrm{C}$. The interior of the chamber was filled with $500 \mu \mathrm{L}$ of DMEM containing 10\% FBS, and the exterior was filled with $100 \mu \mathrm{L}$ of serum-free medium with the prepared cell suspensions. Three replicated wells were used for each group. Transwell chambers were placed into a 24-well plate. A Matrigel-free chamber was employed for incubation of the control group. After $48 \mathrm{~h}$, the transwell chamber was rinsed in PBS, and the cells on the membrane were removed. The chamber was fixed with iced ethanol and stained with crystal violet. Cells at the lower phase of the membrane were enumerated and the experiment was repeated 3 times.

\section{Transwell chamber for cell migration}

The cell migration of all groups of cells was measured in serum-free medium using the transwell chamber according to the instructions of the test kit.

Table 1. Primer sequence

\begin{tabular}{|l|c|c|}
\multicolumn{1}{|c|}{ Gene } & Forward primer 5'-3' & Reverse primer 5'-3' \\
\hline GAPDH & AGTAGTCACCTGTTGCTGG & TAATACGGAGACCTGTCTGGT \\
\hline InCRNAMALAT1 & ACTTACATGTCTGCCTTGG & TCAAAGCTGGTACAGCCA \\
\hline
\end{tabular}




\section{Western blot for TGF- $\beta /$ NF-KB signal pathway activity}

Total proteins were extracted from all groups of HTR8 cells. In brief, lysis buffer was added and proteins were quantified using the Bradford method at $-20^{\circ} \mathrm{C}$ storage for western blot. The proteins were separated using 10\% SDSPAGE and transferred to the NC membrane at $100 \mathrm{~mA}$ for $1.5 \mathrm{~h}$. Primary antibody (TGF- $\beta$ diluted to $1: 2000$ and NF-kB monoclonal antibody diluted to $1: 2000$ ) was added for overnight incubation at $4^{\circ} \mathrm{C}$. The following day, the membrane was rinsed in phosphate-buffered saline with Tween (PBST) and was incubated in goat anti-rabbit secondary antibody diluted to 1:2000 for $30 \mathrm{~min}$ at room temperature in the dark. After PBST rinsing, ECL substrate was added for development for $1 \mathrm{~min}$, followed by X-ray exposure. Protein imaging software and Quantity One software (Bio-Rad, Hercules, USA) were used to scan the X-ray film and measure the band density. All experiments were repeated 4 times $(n=4)$ for statistical analysis.

\section{ELISA for inflammatory cytokine expression in cell culture supernatant}

All samples were measured by the expression of inflammatory cytokines TNF- $\alpha$ and IL- 6 in the supernatant from the cell cultures using ELISA kits and following the test kit manuals. In brief, a 96-well plate was filled with $50-\mu \mathrm{L}$ serially diluted standard samples to prepare the standard curve. Fifty-microliter test samples were added to the wells in triplicate. The plate was then washed and dried. Each well was filled with dilution buffer for washing in a vortex for $30 \mathrm{~s}$. Each well then had $50 \mu \mathrm{L}$ of enzyme-labelled reagent added to it, except for the blank control well. After gentle mixing and incubation at $37^{\circ} \mathrm{C}$ for $30 \mathrm{~min}$, the plate was rinsed 5 times. Chromogenic substrate A and B $(50 \mu \mathrm{L}$ each) were subsequently added into each well for gentle mixing and $37^{\circ} \mathrm{C}$ incubation for $10 \mathrm{~min}$. Fifty microliters of quenching buffer was added into each well in order to stop the reaction. The optical density (OD) values of each well were measured at a wavelength of $450 \mathrm{~nm}$ using a microplate reader.

\section{Statistical processing}

SPSS v. 16.0 (SPSS Inc., Chicago, USA) software was used for statistical analysis. The measurements are presented as means \pm standard deviation (SD). One-way analysis of variance (ANOVA) was used for comparisons of the means among multiple groups. Statistically significant values were recognized when $\mathrm{p}<0.05$.

\section{Results}

\section{Characteristics of patients and controls}

All patients were aged between 22 and 41 years (average age: $27 \pm 5.2$ years) with a body mass index (BMI) of $24.5 \pm 3.2$. The controls - 38 normal pregnant women - were aged between 21 and 42 years (average age: $26 \pm 5.1$ years) and had a BMI of $25.1 \pm 4.6$. No significant differences were observed regarding age or BMI between the control and GDM groups.

\section{Expression of IncRNA MALAT1 in GDM}

Real-time PCR was used to measure the expression of lncRNA MALAT1 in GDM, which showed that it was significantly higher in placental tissues than in normal pregnant placentas ( $\mathrm{p}<0.05$; Fig. 1).

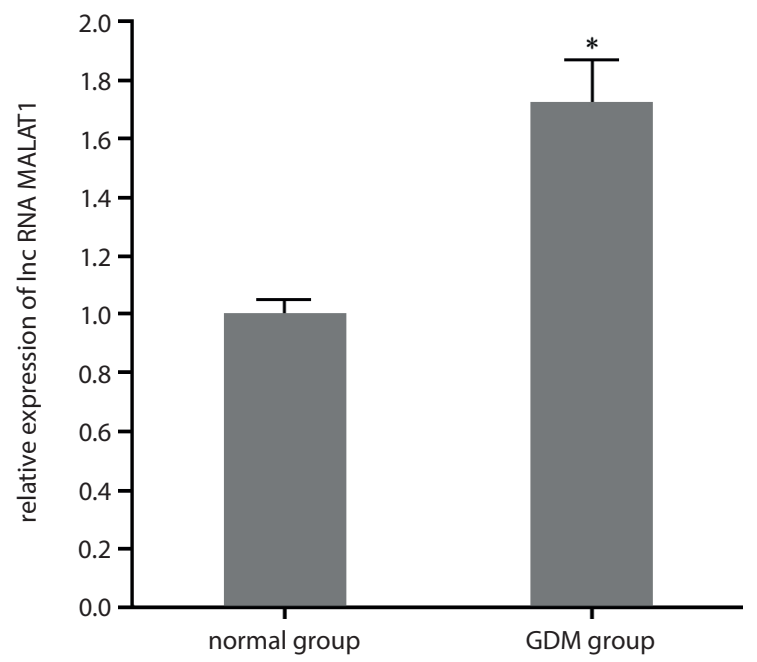

Fig. 1. Expression of IncRNA MALAT1 in GDM

${ }^{*} p<0.05$ compared to the control group.

\section{Effects of siRNA transfection on the expression of IncRNA MALAT1 in trophoblastic cell HTR8}

Compared to the control group and the siRNA-NC group, the HTR8 cells had significantly decreased expression of lncRNA MALAT1 thanks to transfection of lncRNA MALAT1 siRNA ( $<<0.05$; Fig. 2).

\section{Effects of IncRNA MALAT1 knockdown on HTR8 cell proliferation}

To investigate the effect of lncRNA MALAT1 on the proliferation of trophoblastic HTR8 cells, we performed an MTT assay and found that the transfection of lncRNA MALAT1 siRNA for $48 \mathrm{~h}$ significantly suppressed the proliferation of HTR8 cells in comparison to the control group ( $<<0.05$; Fig. 3), indicating that downregulation of lncRNA MALAT1 could inhibit HTR8 cell proliferation. 


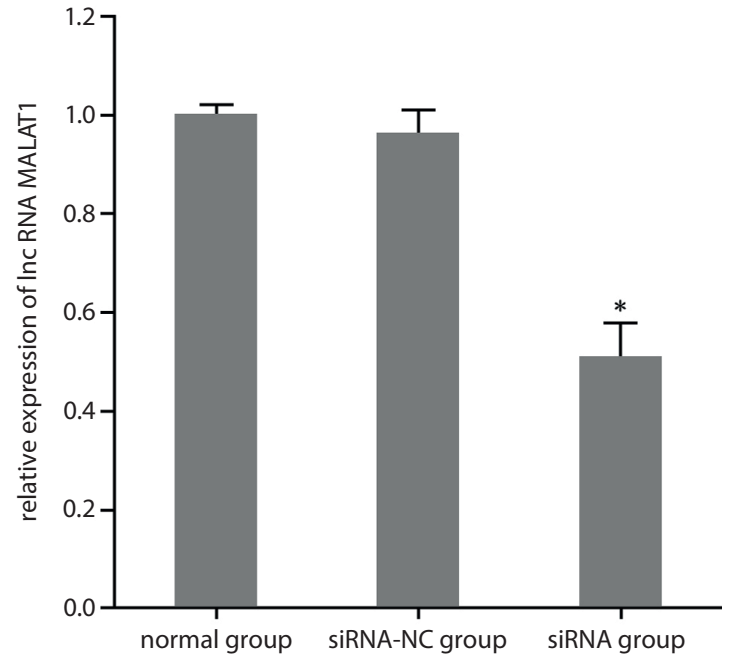

Fig. 2. Expression of IncRNA MALAT1 in trophoblastic cell line HTR8 ${ }^{*} p<0.05$ compared to the control group.

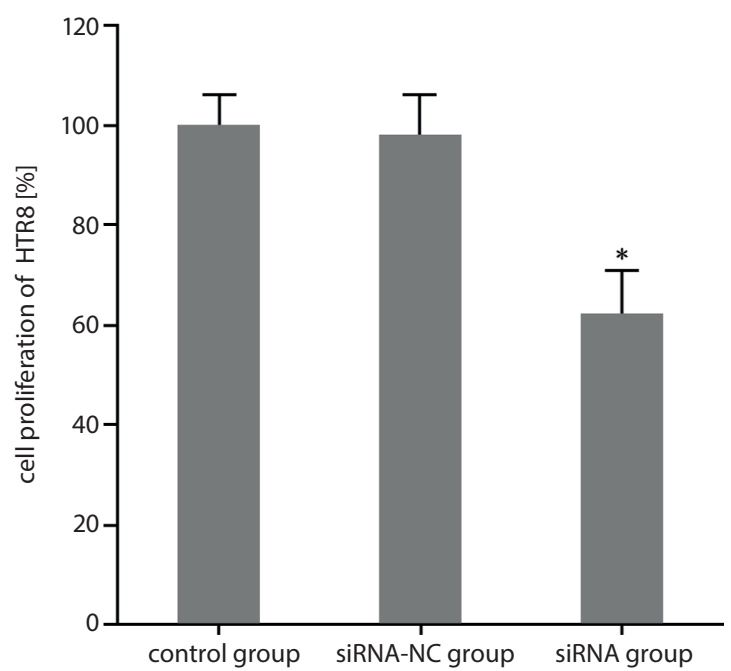

Fig. 3. Effects of IncRNA MALAT1 knockdown on the proliferation of trophoblast cell line HTR8

${ }^{*} p<0.05$ compared to the control group.

\section{Effect of IncRNA MALAT1 knockdown on migration of trophoblast HTR8 cells}

We next investigated the effect of IncRNA MALAT1 on the migration of trophoblastic HTR8 cell using a transwell assay and found that transfection of lncRNA MALAT1 siRNA for $48 \mathrm{~h}$ significantly inhibited the migration of HTR8 cells when compared to the control group ( $<<0.05$; Fig. 4).

\section{Effects of IncRNA MALAT1 knockdown on invasion of trophoblast HTR8 cell}

We also used the transwell approach to analyze the effect of lncRNA MALAT1 knockdown on the invasion of trophoblastic cell line HTR8 and found that the transfection of IncRNA MALAT1 siRNA significantly inhibited invasion of HTR8 cells after $48 \mathrm{~h}$ compared to the control group (p $<0.05$; Fig. 5).

\section{Effects of IncRNA MALAT1 knockdown on inflammatory cytokine expression in the supernatant of trophoblastic cell line HTR8}

The ELISA approach was used to measure the expression of inflammatory cytokines in the supernatant of trophoblastic cell line HTR8 and demonstrated that transfection of lncRNA MALAT1 siRNA for $48 \mathrm{~h}$ significantly inhibited TNF- $\alpha$ and IL- 6 secretion from HTR8 cells in comparison with the control group ( $\mathrm{p}<0.05$; Fig. 6 ).

\section{Effects of IncRNA MALAT1 knockdown on the TGF- $\beta /$ NF-KB signaling pathway}

Western blot was performed to observe the effect of lncRNA MALAT1 knockdown on the TGF- $\beta / N F-k B$ signaling pathway in trophoblastic cell line HTR8. It revealed that the transfection of IncRNA MALAT1 siRNA significantly reduced the expression of TGF- $\beta$ and NF- $\mathrm{kB}$ when compared to the control group ( $\mathrm{p}<0.05 ;$ Fig. 7 ).
A

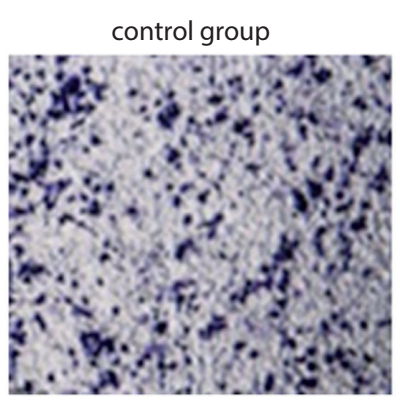

siRNA-NC group

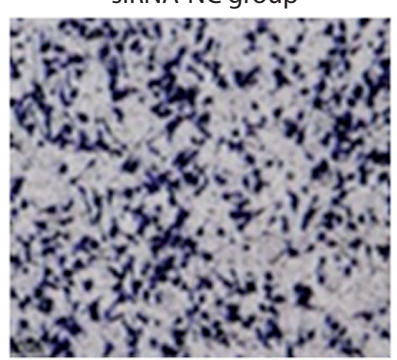

SiRNA group

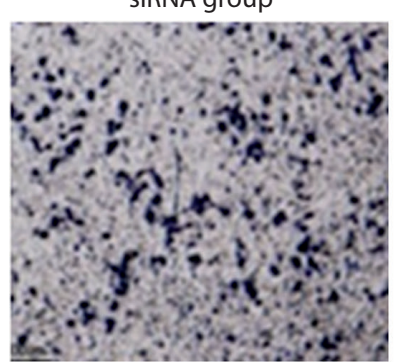

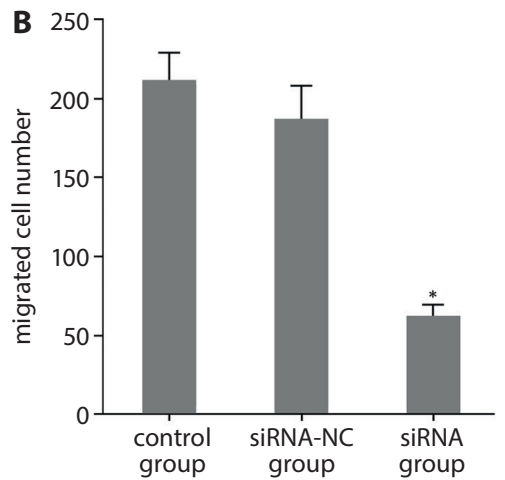

Fig. 4. Effects of IncRNA MALAT1 knockdown on trophoblastic cell HTR8 migration. A. Transwell assay for analyzing the effect of IncRNA MALAT1 knockdown on HTR8 cell migration. B. Analysis for HTR8 cell migration 
A

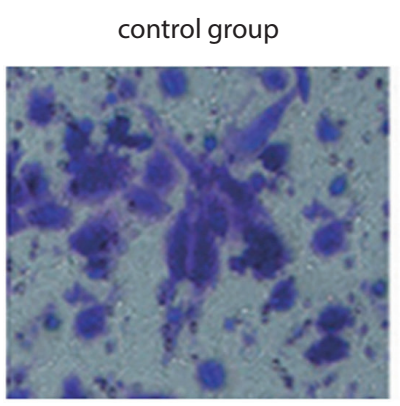

siRNA-NC group

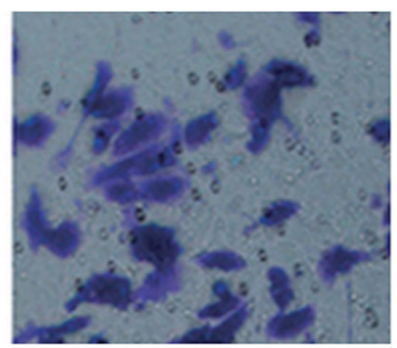

siRNA group

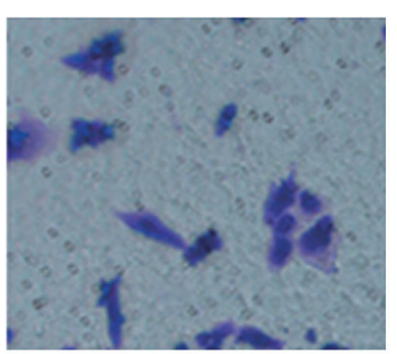

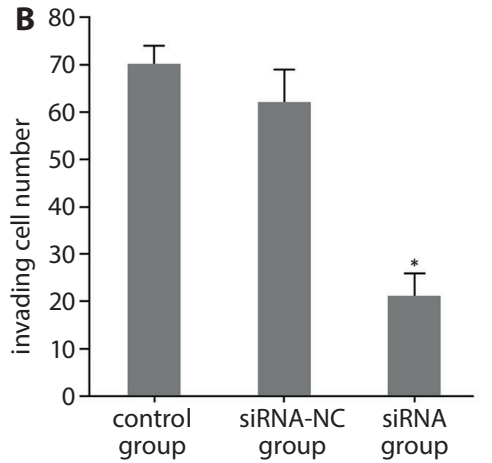

Fig. 5. Effects of IncRNA MALAT1 knockdown on invasion of trophoblast cell HTR8. A. Transwell chamber assay for analyzing the effect of IncRNA MALAT1 knockdown on HTR8 cell invasion. B. Statistical analysis for HTR8 cell invasion

${ }^{*} \mathrm{p}<0.05$ compared to the control group.

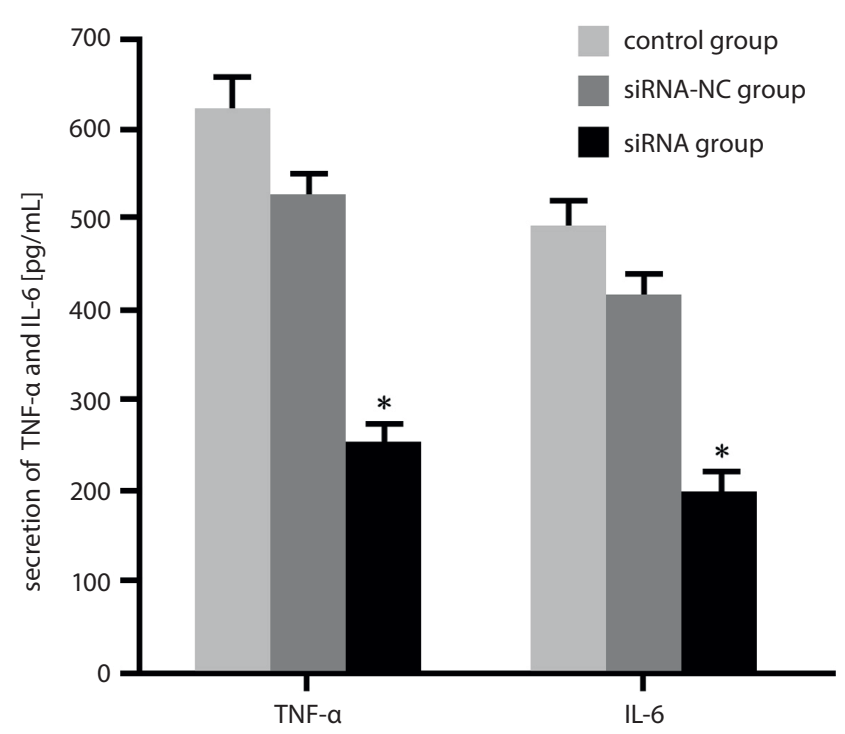

Fig. 6. Effect of IncRNA MALAT1 knockdown on inflammatory cytokine factor of trophoblastic cell line HTR8

${ }^{*} p<0.05$ compared to the control group.

\section{Discussion}

Long non-coding RNA was discovered several years ago. ${ }^{12}$ Large amounts of non-coding RNA transcripts have been found in eukaryotes and they occupy the majority of the human genome. ${ }^{13,14}$ Long non-coding RNA refers to those transcripts longer than $200 \mathrm{nt}$. Due to the irrelevance to protein coding, lncRNA was initially recognized as "background noise" of gene transcription without any biological function. However, through deeper studies, lncRNA has been found to regulate and participate in gene expression regulation at the epigenetic, transcriptional and post-transcriptional levels. ${ }^{15}$ Long non-coding RNA can regulate various physiological events at the genetic level, including chromatin modification, genomic imprinting, nuclear trafficking, chromosomal gene silencing, and transcriptional activation. ${ }^{16}$ In addition, lncRNA can regulate both physiological and pathological conditions of cells, including growth, proliferation, cell cycle, and cell apoptosis, making it a critical regulatory factor
A control group siRNA-NC group siRNA group

TGF- $\beta$

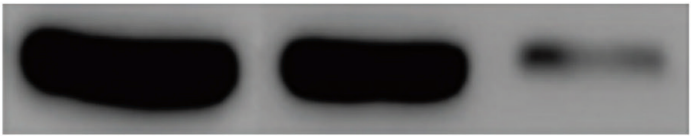

$\mathrm{NF}-\mathrm{KB}$

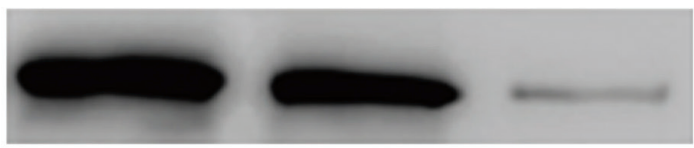

$\beta$-actin

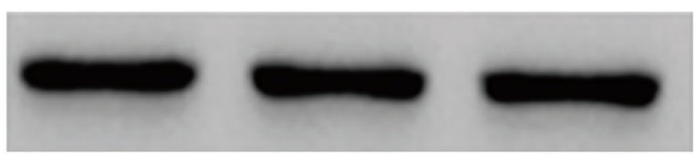

Fig. 7. Effect of IncRNA MALAT1 knockdown on the TGF- $\beta$ /NF-KB signaling pathway in trophoblastic HTR8 cells. A. Western blot for the effect of IncRNA MALAT1 knockdown on the TGF- $\beta / N F-k B$ signaling pathway in trophoblastic cell line HTR. B. Statistical analysis for the TGF- $\beta$ /NF-KB signaling pathway

${ }^{*} p<0.05$ compared to the control group.
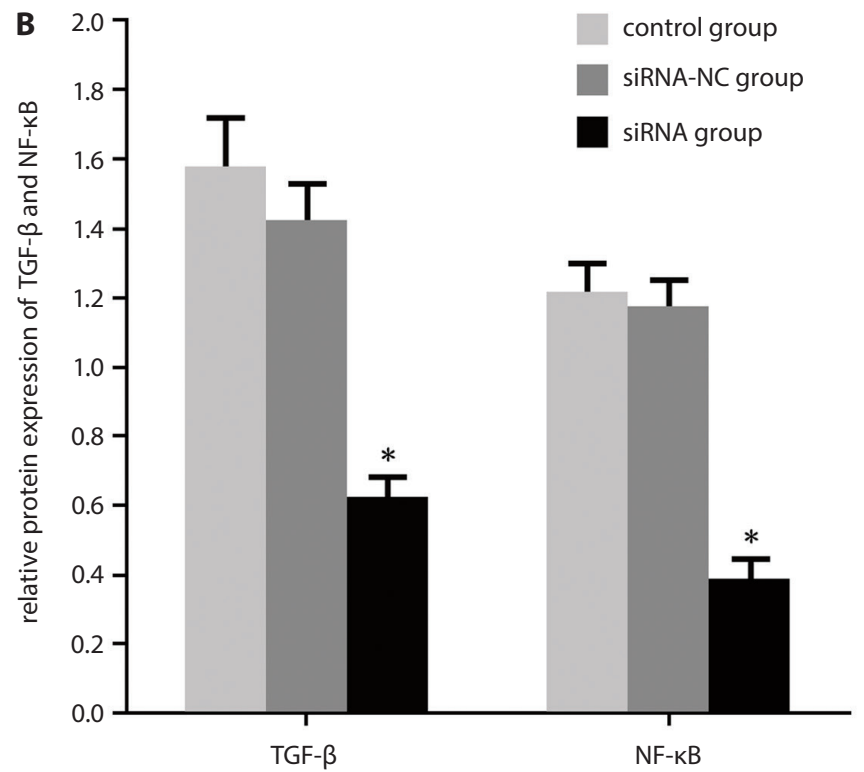
for human disease onset and progression. ${ }^{17}$ However, few studies have been performed regarding its role in GDM. In diabetes, IncRNA MALAT1 has been found to be abnormally expressed, ${ }^{11}$ though the exact role and function of lncRNA MALAT1 in GDM remains poorly understood. This study aimed to investigate the expression of lncRNA MALAT1 in GDM placental tissues. Its expression was found to be upregulated in GDM, indicating that it might be involved in GDM pathogenesis and may affect maternal/fetal health.

We further analyzed the role of lncRNA MALAT1 in GDM and its functional mechanism. As the only maternal-fetal interface and the site for exchange of substances, the placenta is critical for maintaining and protecting normal fetal development. ${ }^{18}$ The placenta can provide a route for the transportation of nutrients between maternal and fetal bodies, and it is an important organ for gas exchange, blood circulation and endocrine function. The placenta is also important for investigating glucose metabolism and endocrine disease. ${ }^{19,20}$ This study thus selected placental trophoblastic cell line HTR8, which was cultured under a high-glucose environment to mimic the conditions of the GDM placental trophoblastic layer. To investigate the role and function of lncRNA MALAT1 in GDM, we transfected lncRNA MALAT1 siRNA into placental trophoblastic cell HTR8 under high-glucose conditions and found that lncRNA MALAT1 downregulation in placental trophoblastic HTR8 cells under highglucose conditions inhibited the proliferation, migration and invasion potency of HTR8 cells. These results indicate that lncRNA MALAT1 might affect placental functions in GDM by regulating the biological behaviors of placental trophoblastic cells. On the other hand, pro-inflammation in GDM frequently leads to disease progression and body immune disorder. ${ }^{21}$ This study also demonstrated that lncRNA MALAT1 downregulation can inhibit inflammation, possibly by suppressing the secretion of inflammatory factors. The TGF- $\beta / N F-\kappa B$ signaling pathway has been demonstrated to play a role in transcriptional regulation, it is closely related with cell ontogenesis, invasion and metastasis, it can regulate the cytokine network, and it is closely correlated with GDM pathogenesis. ${ }^{22}$ The findings of this study are consistent with this, showing that the downregulation of lncRNA MALAT1 inhibited the TGF- $\beta / N F-\kappa B$ signaling pathway, suggesting that lncRNA MALAT1 affects the biological behaviors of HTR8 cells, possibly through regulating the TGF- $\beta / \mathrm{NF}-\mathrm{kB}$ signaling pathway. However, the exact mechanism by which lncRNA MALAT1 regulates the TGF- $\beta / N F-\kappa B$ signaling pathway remains unclear. In addition, the exact molecular mechanism by which lncRNA MALAT1 is involved in the pathogenesis of GDM remains poorly understood. Future studies are required to investigate these issues in order to provide more evidence for GDM pathogenesis and clinical treatment.

\section{Conclusions}

The GDM patients present upregulation of lncRNA MALAT1. Downregulation of lncRNA MALAT1 inhibits the proliferation, invasion and migration of GDM placental trophoblastic cells, possibly by modulating the TGF- $\beta$ / $\mathrm{NF}-\mathrm{\kappa} \mathrm{B}$ signaling pathway.

\section{ORCID iDs}

Yan Zhang (D) https://orcid.org/0000-0002-7929-8369 Liping Qu (D) https://orcid.org/0000-0002-8413-1838 Huijie Ni (D) https://orcid.org/0000-0003-0537-0513 Yuping Wang (i) https://orcid.org/0000-0003-4583-4634 Lei Li (D) https://orcid.org/0000-0002-4456-2983 Xiaowei Yang (D) https://orcid.org/0000-0002-0841-7703 Xiao Wang (D) https://orcid.org/0000-0002-5474-3411 Yuanyuan Hou (D) https://orcid.org/0000-0002-5925-3702

\section{References}

1. Riaz SH, Khan MS, Jawa A, Hassan M, Akram J. Lack of uniformity in screening, diagnosis and management of gestational diabetes mellitus among health practitioners across major cities of Pakistan. Pak J Med Sci. 2018;34(2):300-304.

2. Kashyap H, Sharma D, Gala A, Tejo Pratap O, Murki S. Effect of second trimester and third trimester weight gain on immediate outcomes in neonates born to mothers with gestational diabetes: A retrospective observational study from India. JMatern Fetal Neonatal Med. 2019;32(24):4133-4138.

3. Carroll X, Liang X, Zhang W, et al. Socioeconomic, environmental and lifestyle factors associated with gestational diabetes mellitus: A matched case-control study in Beijing, China. Sci Rep. 2018;8(1):8103.

4. Beyerlein A, Lack N, von Kries R. No further improvement in pregnancy-related outcomes in the offspring of mothers with pre-gestational diabetes in Bavaria, Germany, between 2001 and 2016. Diabet Med. 2018;35(10):1420-1424.

5. Zhou JL, Xing J, Liu CH, et al. Effects of abnormal $75 \mathrm{~g}$ oral glucose tolerance test at different time points on neonatal complications and neurobehavioral development in the pregnant women with gestational diabetes mellitus (a STROBE-compliant article). Medicine (Baltimore). 2018;97(21):e10743.

6. Rotem R, Fishman B, Daniel S, Koren G, Lunenfeld E, Levy A. Risk of major congenital malformations following first trimester exposure to vaginal azoles used for treating vulvovaginal candidiasis: A population-based retrospective cohort study. BJOG. 2018;125(12): 1550-1556.

7. Looman M,SchoenakerD, Soedamah-MuthuSS, Geelen A, Feskens EJM, Mishra GD. Pre-pregnancy dietary carbohydrate quantity and quality, and risk of developing gestational diabetes: The Australian Longitudinal Study on Women's Health. Br J Nutr. 2018;120(4):435-444.

8. Kim M, Park J, Kim SH, et al. The trends and risk factors to predict adverse outcomes in gestational diabetes mellitus: A 10-year experience from 2006 to 2015 in a single tertiary center. Obstet Gynecol Sci. 2018;61(3):309-318.

9. Garmendia ML, Corvalan C, Casanello P, et al. Effectiveness on maternal and offspring metabolic control of a home-based dietary counseling intervention and DHA supplementation in obese/overweight pregnant women (MIGHT study): A randomized controlled trial-study protocol. Contemp Clin Trials. 2018;70:35-40.

10. Reece SW, Parihar HS, Martinez M. Retrospective review of maternal and fetal outcomes in patients with gestational diabetes mellitus in an indigent prenatal clinic. Diabetes Spectr. 2018;31(2):200-205.

11. Biswas $S$, Thomas AA, Chen $S$, et al. MALAT1: An epigenetic regulator of inflammation in diabetic retinopathy. Sci Rep. 2018;8(1):6526.

12. YeH, Liu K, Qian K. Overexpression of long noncoding RNA HOTTIP promotes tumor invasion and predicts poor prognosis in gastric cancer. Onco Targets Ther. 2016;9:2081-2088.

13. Wang SH, Wu XC, Zhang MD, Weng MZ, Zhou D, Quan ZW. Upregulation of $\mathrm{H} 19$ indicates a poor prognosis in gallbladder carcinoma and promotes epithelial-mesenchymal transition. Am J Cancer Res. 2016;6(1):15-26. 
14. Zhang SR, Yang JK, Xie JK, Zhao LC. Long noncoding RNA HOTTIP contributes to the progression of prostate cancer by regulating HOXA13. Cell Mol Biol (Noisy-le-grand). 2016;62(3):84-88.

15. Chang L, Qi H, Xiao Y, et al. Integrated analysis of noncoding RNAs and mRNAs reveals their potential roles in the biological activities of the growth hormone receptor. Growth Horm IGF Res. 2016;29:11-20.

16. Li P, Zhang G, Li J, et al. Long noncoding RNA RGMB-AS1 indicates a poor prognosis and modulates cell proliferation, migration and invasion in lung adenocarcinoma. PLoS One. 2016;11(3):e0150790.

17. Zhang H, Cai Y, Zheng L, Zhang Z, Lin X, Jiang N. Long noncoding RNA NEAT1 regulate papillary thyroid cancer progression by modulating miR-129-5p/KLK7 expression. J Cell Physiol. 2018;233(10):6638-6648.

18. Chen H, Zhou X, Han TL, Baker PN, Qi H, Zhang H. Decreased IL-33 production contributes to trophoblast cell dysfunction in pregnancies with preeclampsia. Mediators Inflamm. 2018;2018:9787239.
19. Deng Q, Liu X, Yang Z, Xie L. Expression of N-acetylglucosaminyltransferase III promotes trophoblast invasion and migration in early human placenta. Reprod Sci. 2018;26(10):1373-1381.

20. Peng HY, Li MQ, Li HP. High glucose suppresses the viability and proliferation of HTR8/SVneo cells through regulation of the miR137/ PRKAA1/IL6 axis. Int J Mol Med. 2018;42(2):799-810.

21. Chow JY, Ban M, Wu HL, et al. TGF-beta downregulates PTEN via activation of NF-kappaB in pancreatic cancer cells. Am J Physiol Gastrointest Liver Physiol. 2010;298(2):G275-G282.

22. Sriramula S, Francis J. Tumor necrosis factor alpha is essential for angiotensin II-induced ventricular remodeling: Role for oxidative stress. PLoS One. 2015;10(9):e0138372. 